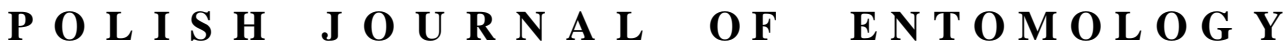

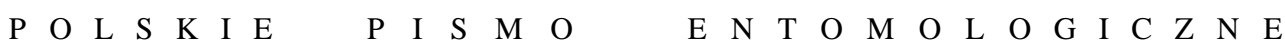

VOL. 83: 61-69

Lublin

31 March 2014

DOI: $10.2478 /$ pjen-2014-0004

\section{New faunistic records of the subfamily Sympycninae (Diptera, Dolichopodidae) from Iran}

\author{
FARZANEH KAZERANI $^{1}$, SAMAD KHAGHANINIA ${ }^{1}$, IGOR GRICHANOV ${ }^{2}$ \\ ${ }^{1}$ Department of Plant Protection, Faculty of Agriculture, University of Tabriz, 51664, \\ Tabriz, I.R. Iran, e-mail: skhaghaninia@gmail.com \\ ${ }^{2}$ All-Russian Institute of Plant Protection, Podbelskogo 3, 196608 St. Petersburg, \\ Pushkin, Russia
}

\begin{abstract}
Faunistic data is given for 4 species of the subfamily Sympycninae, new to the fauna of Iran. The specimens were collected in north-western Iran during 2013. The following species are recorded for the first time in this country: Campsicnemus curvipes (FALLÉN, 1823), C. umbripennis LOEW, 1856, Sympycnus pulicarius (FALLÉN, 1823) and Syntormon pumilus (MEIGEN, 1824). The genus Campsicnemus HALIDAY, 1851 is newly reported from the country. Lists of the genera and species along with diagnostic characters, geographical distribution and supplementary figures of the species in question are given.
\end{abstract}

KEY WORDS: Dolichopodidae, Sympycninae, Iran, fauna, new records.

\section{INTRODUCTION}

The Dolichopodidae is a very large family of the order Diptera with more than 7500 species described. Most species of this family are polyphagous predators feeding on various small invertebrates, but the adults of some species are known to feed on nectar (GRICHANOV 2007, GRICHANOV et al. 2011). The subfamily Sympycninae comprises about 10 genera and 65 species in the eastern Mediterranean, and 11 genera in the Palaearctic region (GRICHANOV 2007, GRICHANOV et al. 2011). Morphologically it differs from the most closely related subfamilies (like Rhaphiinae, Hydrophorinae and Diaphorina) by the following combination of characters: postvertical setae, if present, near vertex; head usually 
ovate in anterior view, higher than wide; anal angle often reduced or lost; antenna usually set high on head, about one-quarter distance from vertex; palpus usually small, although sometimes enlarged in males only; posterior mesonotum not flattened, or at most only slightly or apparently flattened immediately anterior of scutellum, postorbital setae usually as distinct row of setae on lower postcranium, even if pale coloured; crossvein $d m-c u$ usually shorter than distal section of $\mathrm{CuA}_{1}$; mid and/or hind femora with distinct anterior preapical seta, male tarsomere 5 rarely with enlarged pulvilli, fore tibia often with anterodorsal row of short setae on distal half; lateral seta of hind coxa usually near middle; abdomen usually ovate, and rarely dorsoventrally flattened. GERMANN et al. (2011) mentioned that Peloropeodinae and Sympycninae are separate subfamilies and placed Palaearctic species of two genera (Chrysotimus LOEW, 1857, and Micromorphus MILK, 1878) as a clade of Peloropeodinae.

The Iranian fauna of Sympycninae is poorly known. Before this study, BECKER \& STEIN (1913) reported Syntormon pallipes (FABRICIUS, 1794), NEGROBOV \& MATILE (1974) described two species of the genus Syntormon (S. giordanii Negrobov, 1974, and S. iranicus NEgROBOV, 1974) from Iran, and GRICHANOv et al. (2010) added Sympycnus simplicipes BECKER, 1908 and Syntormon zelleri (LOEW, 1850) of this subfamily to the Iranian fauna.

\section{MATERIALS AND METHODS}

Materials were collected using a standard entomological hand net from grassland and semi-aquatic habitats in 3 regions of north-western Iran during 2013. They were preserved in $75 \%$ ethanol in glass vials. The specimens are deposited at the Insect Museum of Tabriz University (IMTU). The species are listed below in alphabetical order. The distribution part of the list includes neighbouring countries and notes on the general distribution of each species after GRICHANOV (2007) and GRICHANOv's online database DoliBank (available from http://dolicho.narod.ru/Genera3.htm).

\section{RESULTS}

In this study, four species of three genera belonging to the subfamily Sympycninae are recognised. All species (Campsicnemus curvipes (FALLÉN, 1823), C. umbripennis LOEW, 1856, Sympycnus pulicarius (FALLÉN, 1823) and Syntormon pumilus (MEIGEN, 1824)) and the genus Campsicnemus HALIDAY, 1851 are recorded from Iran for the first time. 


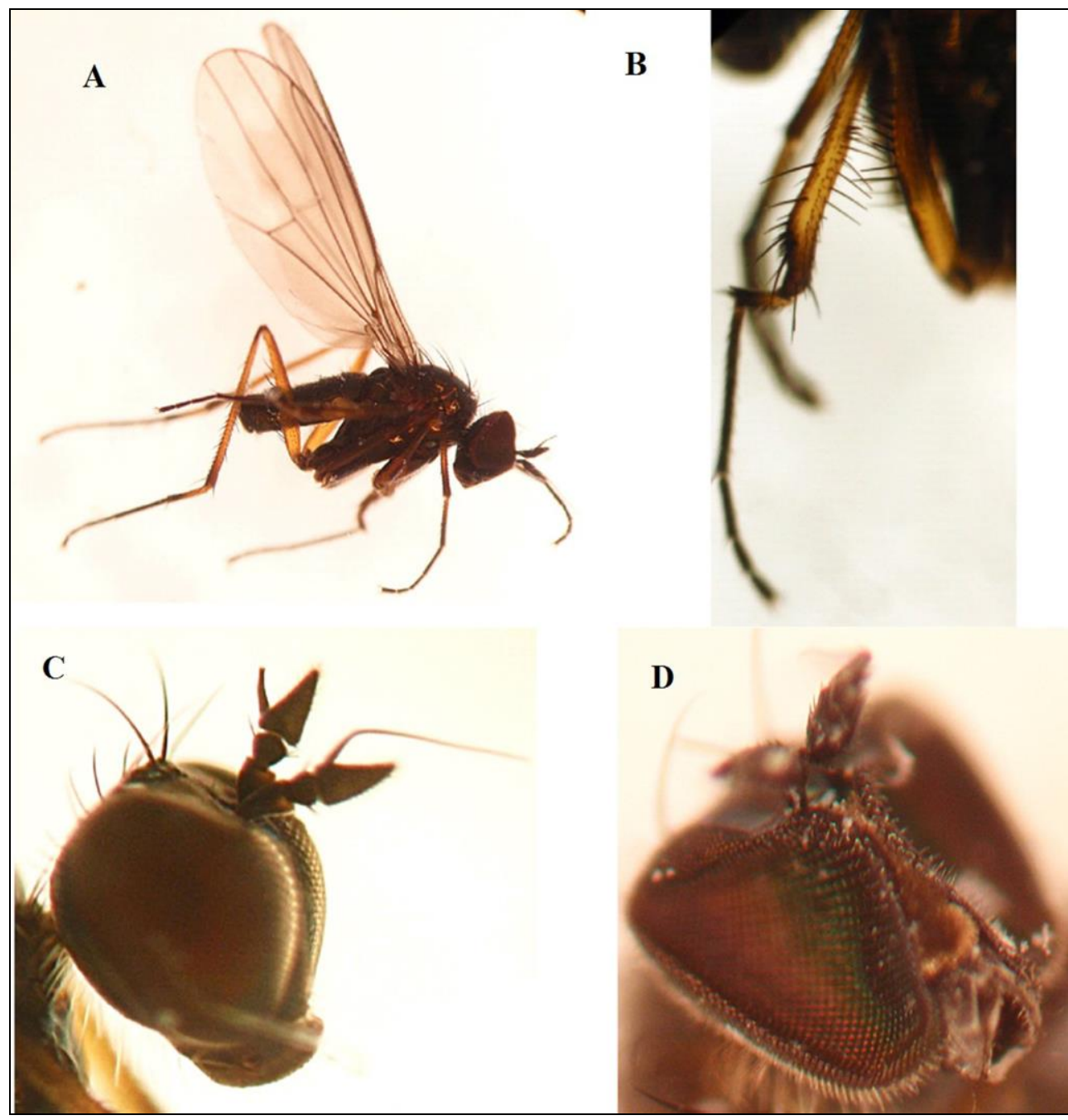

Fig. 1. Campsicnemus curvipes; A) male habitus, lateral view; B) mid leg; C) head, lateral view; D) head, frontal view.

\section{Campsicnemus curvipes (FALLÉN, 1823)}

(Fig. 1)

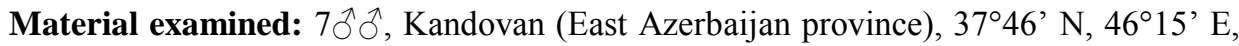
2341 m, 25 VII 2013; leg. S. KHAGHANINIA.

Distribution: Abkhazia, Algeria, Armenia, Austria, Azerbaijan, Belarus, Belgium, Bulgaria, Czech Republic, Denmark, Estonia, Finland, former Yugoslavia, France, Georgia, 
Germany, Greece incl. Crete, Hungary, Ireland, Italy, Latvia, Luxembourg, Macedonia, Morocco, Netherlands, Norway, Poland, Portugal (Azores, Madeira), Romania, Russia (Adygea, Alania, Dagestan, Kabardino-Balkaria, Kaluga, Karelia, Karachai-Cherkessia, Stavropol, Krasnodar, Krasnoyarsk, Leningrad, Moscow, Pskov, Ryazan), Slovakia, Slovenia, Spain incl. Canary Is., Sweden, Switzerland, Turkey, Ukraine (Crimea, Odessa), UK.

Diagnostic characters: Antenna entirely black (Fig. 1C); face narrow in middle, extending downward (Fig. 1D); legs reddish-yellow, sometimes partly brown (Fig. 1A), fore tarsus without long processes, mid tibia distinctly thickened in distal half, with several dorsal setae in apical half, mid basitarsus shortened, mid femur with row of black ventral setae (Fig. 1B).

\section{Campsicnemus umbripennis LOEW, 1856}

(Fig. 2)

Material examined: $10{ }^{\lambda}, 6$ 우우, Kandovan (East Azerbaijan province), 37 $46^{\prime} \mathrm{N}$,

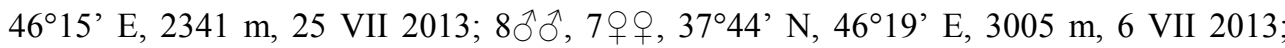

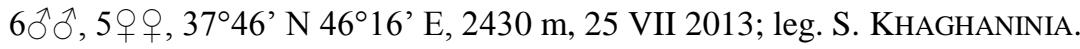

Distribution: Abkhazia, Afghanistan, Armenia, Austria, Azerbaijan, Belgium, Bulgaria, Czech Republic, former Yugoslavia, France, Georgia, Germany, Greece incl. North Aegean, Hungary, Iraq, Italy, Israel, Poland, Portugal, Romania, Russia (Adygea, Alania, Kabardino-Balkaria, Karachai-Cherkessia, Krasnodar); Slovakia, Spain, Switzerland, Tajikistan, Turkey, Turkmenistan, UK.

Diagnostic characters: Male: antenna entirely black (Fig. 2D); wing dark or brown, long and narrow, without anal lobe; legs mainly black-brown; fore leg simple, fore tarsus without enlarged segments (Fig. 2A), mid basitarsus 1.5-2 times shorter than next segment, mid tibia with remarkable setae and not swollen in basal third, mid femur with double ventral row of short setae of equal length (Fig. 2E); female: face grey-brown (Fig. 2C); antenna entirely black; wing long and narrow, dark-fumose; legs long and thin, legs black, at most with light knees or with partly yellow hind tibia (Fig. 2B).

\section{Sympycnus pulicarius (FALLÉN, 1823)}

(Fig. 3)

Material examined: $3 \widehat{\partial}^{\lambda}{ }^{\lambda}$, Khoy (West Azerbaijan province), $37^{\circ} 46^{\prime} \mathrm{N} 46^{\circ} 16^{\prime} \mathrm{E}, 2430$ m, 02 VII 2013; leg. S. KHAGHANINIA.

Distribution: Azerbaijan, Bulgaria, Greece incl. North Aegean, Romania, S Russia (Alania, Kabardino-Balkaria, Karachai-Cherkessia, Stavropol'), E Russia (Altai), Turkey, Ukraine (Crimea, Kherson); all Europe; Nearctic: California. 


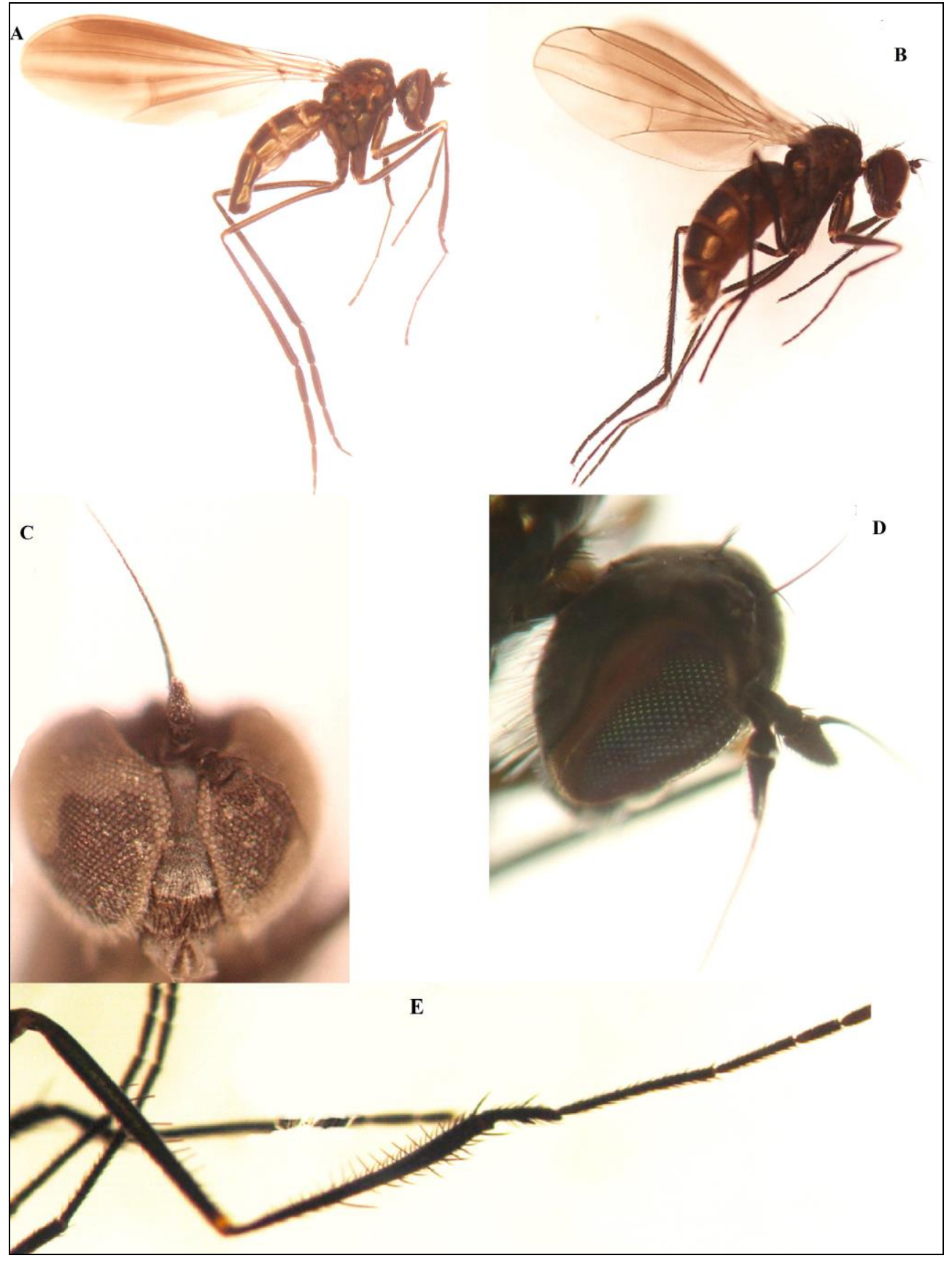

Fig. 2. Campsicnemus umbripennis; A) male habitus, lateral view; B) female habitus, lateral view; C) female head, frontal view; D) male, head, lateral view; E) male, mid leg. 


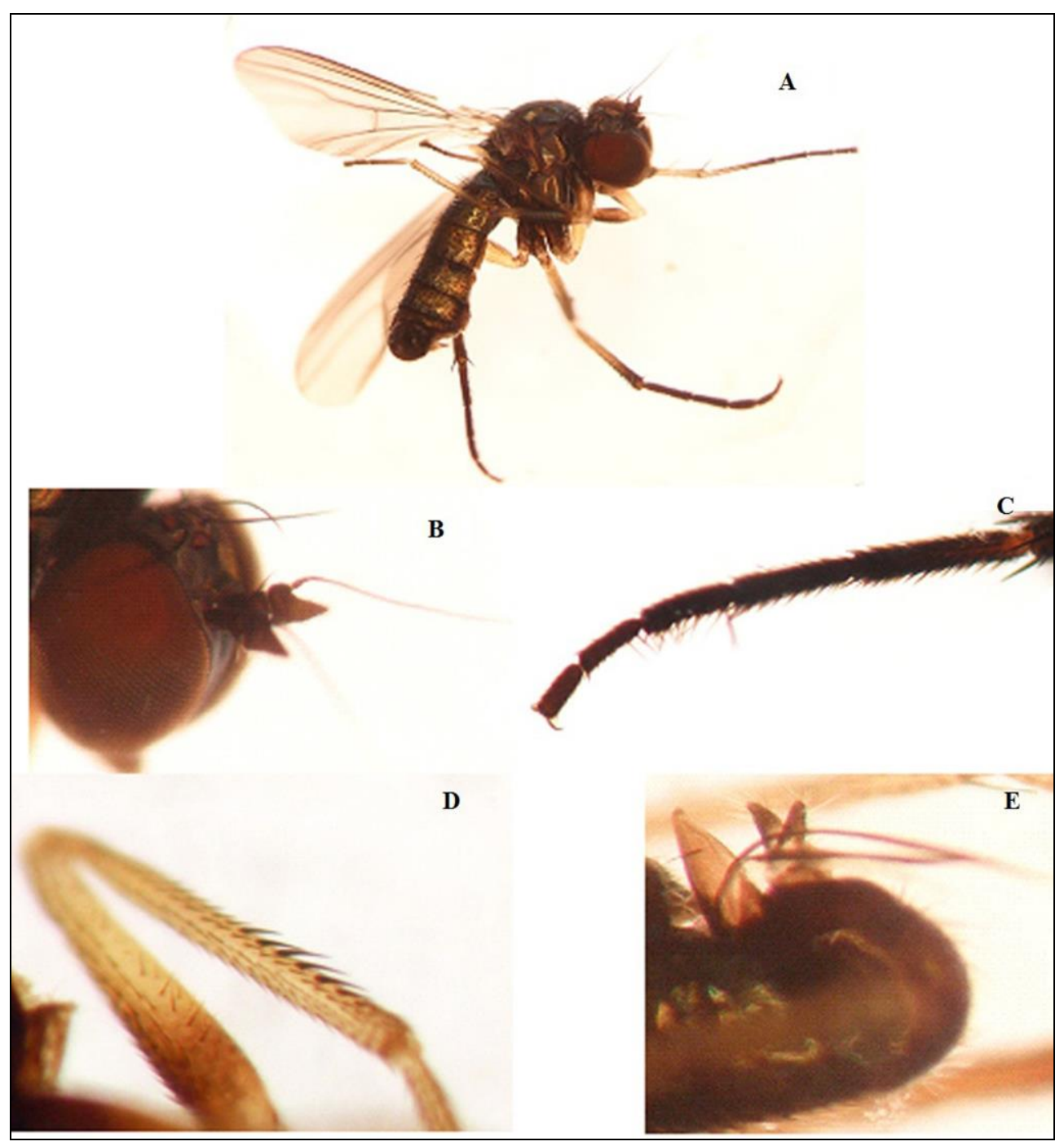

Fig. 3. Sympycnus pulicarius, male; A) habitus, lateral view; B) head, lateral view; C) hind basitarsus; D) front tibia; E) hypopygium, lateral view.

Diagnostic characters: Antenna entirely black, stylus basodorsal (Fig. 3B); fore coxa mainly, and fore femur largely, black, fore tibia dorsally, at least on apical half, with a row of short strong black spines (Fig. 3D), mid and hind femora mainly yellow, hind tarsus with 3rd and 4th segments laterally compressed with much longer cilia along whole length of 3rd segment and on basal third of 4th (Fig. 3C); hypopygium as in Fig. 3E. 


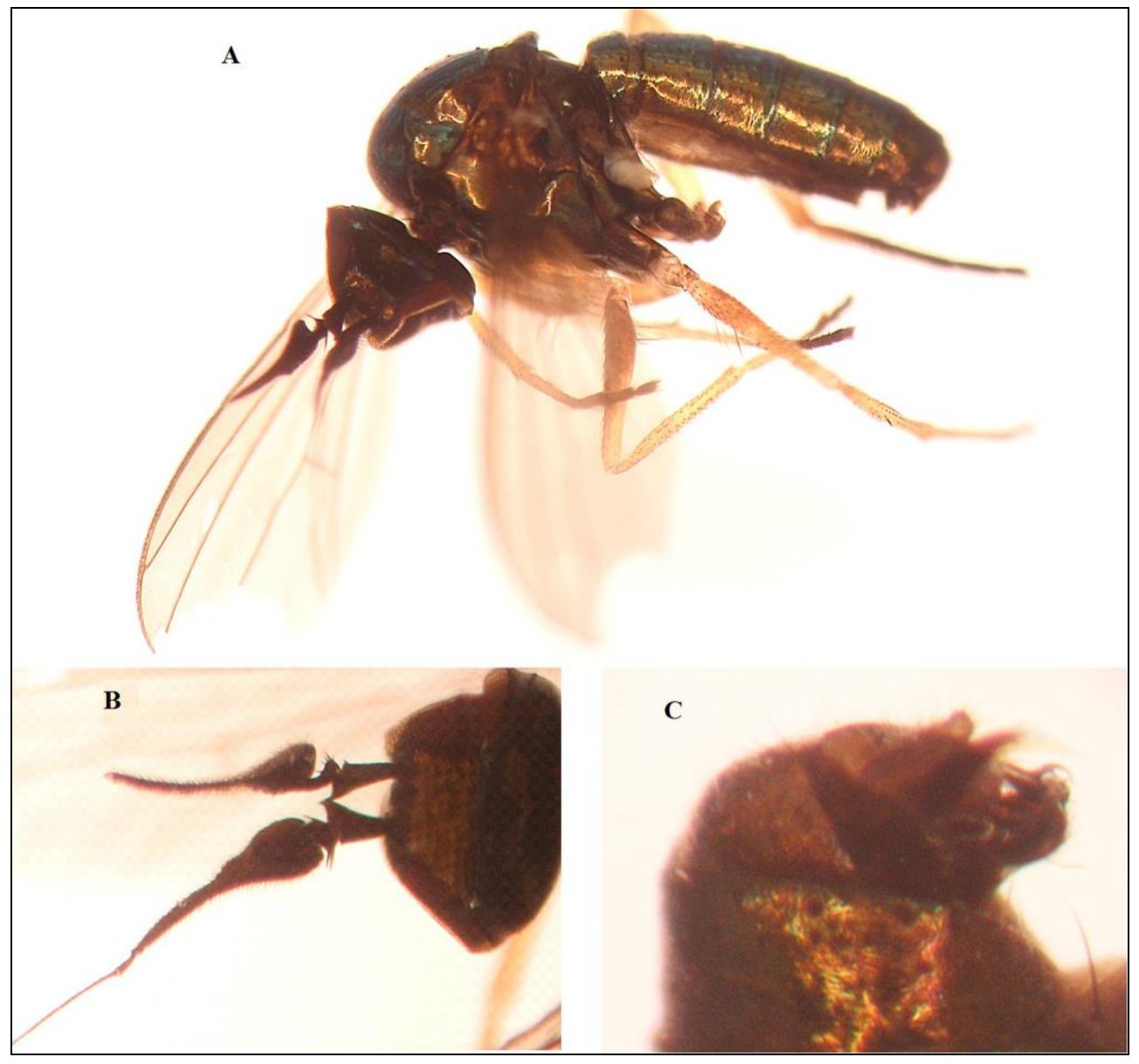

Fig. 4. Syntormon pumilus; A) male habitus, lateral view; B) head, dorsal view; C) hypopygium, lateral view.

\section{Sympycnus pumilus (MEIGEN, 1824)}

(Fig. 4)

Material examined: $10^{\lambda}$, Ghirx-bulax, Meshkin Shahr (Ardabil province), $38^{\circ} 18^{\prime} \mathrm{N}$ 47²3’ E, 1803 m, 10 VIII 2013; leg. S. KHAGHANinia.

Distribution: Afghanistan, Armenia; Austria, Belarus, Belgium, Bulgaria, Czech Republic, Denmark, Egypt, Estonia, Finland, former Yugoslavia, France, Germany, Greece, Hungary, Ireland, Israel, Italy, Latvia, Morocco, Norway, Poland, Romania; Russia (Astrakhan, Kabardino-Balkaria, Kaluga, Karelia, Krasnodar, Kursk, Leningrad, Lipetsk, 
Moscow, Murmansk, Novosibirsk, Pskov, Stavropol, Vologda, Voronezh, Yakutia), Slovakia, Slovenia, Sweden, Spain (Canary Is.), Tunisia, Turkey, UK, Ukraine (Kherson, Odessa), "Central Asia".

Diagnostic characters: Lower postocular setae yellow; antenna dark, postpedicel elongate-triangular, rarely short, with apical stylus (Fig. 4B); acrostichals irregularly uniseriate; fore femur with 3-4 ventral setae at base, fore femur with several black ventral setae at base; 2nd segment of fore tarsus with more or less developed apical triangular prolongation; 4th segment of same tarsus with dorsal seta; fore tarsus with shortened 2nd4th segments; each segment hardly longer than wide; mid femur with several long ventral cilia in basal half, hind basitarsus simple; abdomen entirely dark (Fig. 4A); hypopygium as in Fig. 4C.

\section{DISCUSSION}

All four species were collected in grassland areas. Their populations found in this study were small, hence we can conclude that these species are rare in the north-west of Iran, except for C. umbripennis, which occurs in dense populations in the Kandovan region, a mixed area of rich grasslands with various species of Asteraceae, Apiaceae, Leguminaceae, Poaceae and Ranunculaceae, as well as various crops. Since all these species are predators on soft-bodied insects like aphids, mites and midges, they can serve as agents of pest population control and possibly natural pollinators in the grassland areas.

\section{REFERENCES}

BeCKeR T.H., SteIN P. 1913. Persische Dipteren von den Expeditionen des Herrn N. ZARUDNY 1898 und 1901. Ezhegodnik Zoologicheskogo Muzeya Imperatorskoï Akademii Nauk 17(3-4): 503-654.

Germann C., Pollet M., Wimmer C., Bernasconi M.V. 2011. Molecular data sheds light on the classification of long-legged flies (Diptera: Dolichopodidae). Invertebrate Systematics 25(4): 303-321.

GRICHANOV I.YA. 2003-2013. A check list of species of the family Dolichopodidae (Diptera) of the World arranged by alphabetic list of generic names [online database]. Available from http://dolicho.narod.ru/Genera3.htm [accessed 20 July 2013].

GRICHANOV I.YA. 2007. A checklist and keys to Dolichopodidae (Diptera) of the Caucasus and East Mediterranean. Plant Protection News (Supplement): 1-160.

Grichanov I.YA., Alikhani M., RabiEH M.M. 2010. New data on the distribution of Dolichopodidae (Diptera) in Iran. The International Journal of Dipterological Research 21(3): 195-201. 
Grichanov I.YA., Selivanova O.V., NegrobOV O.P. 2011. A brief synopsis of Palaearctic genera of the family Dolichopodidae (Diptera). Ukrainska Entomofaunistika 2(2): 11-40.

Negrobov O.P., MatiLe L. 1974. Contribution à la faune de l'Iran: Diptera, Dolichopodidae. Annales de la Société Entomologique de France 10(4): 841-845.

Received: 5 November 2013

Accepted: 13 January 2014 